IRA-International Journal of Management \& Social Sciences

ISSN 2455-2267; Vol.05, Issue 02 (2016)

Pg. no. 265-276

Institute of Research Advances

http://research-advances.org/index.php/RAJMSS

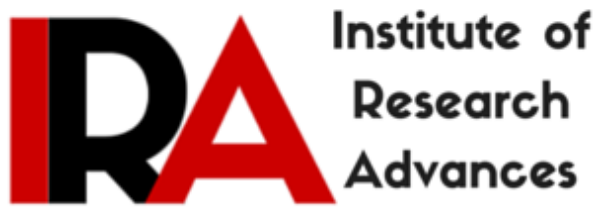

\title{
The Physician-Patient Relationship: A Review of Two Theoretical Approaches and Health Regulation Implications
}

\author{
Andre Yitambe $(\mathrm{PhD})$ \\ Chairman and Senior Lecturer, \\ Department of Health Management and Informatics School of Public Health Kenyatta \\ University Nairobi - Kenya.
}

Peterson N. Warutere, $(\mathrm{PhD})$

Chairman, Department of Environmental Health, School of Public Health

Kenyatta University, Nairobi, Kenya

Kenneth R. Kibaara, $(\mathrm{PhD})$

Department of Health Management and Informatics, School of Public Health

Kenyatta University, Nairobi, Kenya.

Type of Review: Peer Reviewed.

DOI: http://dx.doi.org/10.21013/jmss.v5.n2.p6

\section{How to cite this paper:}

Yitambe, A., Warutere, P., Kibaara, K. (2016). The Physician-Patient Relationship: A Review of Two Theoretical Approaches and Health Regulation Implications. IRA-International Journal of Management \& Social Sciences (ISSN 2455-2267), 5(2), 265-276. doi:http://dx.doi.org/10.21013/jmss.v5.n2.p6

(C) Institute of Research Advances

\section{(cc) EY-No}

This work is licensed under a Creative Commons Attribution-Non Commercial 4.0 International License subject to proper citation to the publication source of the work.

Disclaimer: The scholarly papers as reviewed and published by the Institute of Research Advances (IRA) are the views and opinions of their respective authors and are not the views or opinions of the IRA. The IRA disclaims of any harm or loss caused due to the published content to any party. 


\section{ABSTRACT}

Recent development in the organization of healthcare has impacted on physician and patient relationship. The physician-patient relationship is becoming more and more a universalistic concern. Since Hippocrates, the physician-patient relationship remains the corner stone of medical practice. A number of disciplines have questioned the interaction between physician and patient (from pure sciences and clinical sciences to social sciences). This paper uses a de-centered comparative method to examine how different theoretical approaches shape the understanding of doctor-patient interaction and health regulation implications. In particular, the article looks at two theoretical models: health economics and medical socio-anthropology. The findings show that the difference between the two approaches is based upon the background of each discipline. Nevertheless, there are some similarities. The paper concludes that no theoretical approach is totally privileged to understand the interaction.

Key words: physician-patient relationship, health economics, medical socio-anthropology, health regulation.

\section{INTRODUCTION}

The physician-patient remains the corner stone of medical practice. At the same time it is one of the complex interactions in healthcare. On the one side of the interaction stands the physician who diagnosing skills, prescribing patterns and referral decisions determines not only health outcomes but also, and to a greater extent, contribute to health costs. On the other side stands the patient or health demander who is increasingly empowered to make decisions. The interaction arise numerous concerns. In particular, we use in the article two theoretical approaches to explore the interaction: health economics and medical socio-anthropology.

Health economist and health regulators realize the importance of the relationship on health system put great effort into exploring its underlying mechanism. In the interaction one party is a producer of health and the second party is the consumer of health. Both parties are main actors of the health system. Despite the information asymmetry each of the actors would like to maximize the utility or satisfaction derived from the service provided and the service received: the physician's and patient utility. A number of models describe the physician's and patient's utility (McGuire, Costa-Font, 2012). Different payment schemes are designed to change the physician's behavior in many health systems. But challenges remain so far on physician's utility function compared to patient-utility function. The medical socio-anthropology is also used to explain the interaction.

From the medical socio-anthropological approach, in the recent decades, two trends have challenged this state and call for more attention to be given to patient side. The first one is the increasing empowerment of the patient's role in decision making (Kaba; Soriakumaran, 2007). Patients may require more information during the consultation and more actively involved in the choice of the treatment. The empowerment of the patients goes against the paternalistic approach medical practice that has influenced the interaction since Hippocrates.

The second trend is the emergent and re-emergent diseases. The majority of these diseases, including cardiovascular diseases, cancers, diabetes are more related to lifestyle choices. In Low income countries the majority of the conditions including communicable disease, HIV/AIDS and tuberculosis are more related to prevention than treatment. Understanding the patient's role in medical decision is crucial for health economists and health regulators. In that respect, health economists may greatly benefit from medical socio-anthropology which offers elements enabling a better understanding of this relationship. In particular, we review the two approaches of the doctor-patient relationship, consider the recent research trends and discuss the implications for health regulation, economy and society. 


\section{MATERIALS AND METHODS}

This is an ethno-monographic paper on the physician-patient relationship. Using a de-centered comparative method (Wrede et al 2006), we consider how the different theoretical approaches: health economics medical socio-anthropology shape the content and boundaries of understanding the physicianpatient relationship and regulation implications, economy and society. The pathway process of the two theoretical approaches in influenced is influenced by education, practical, acquisition of knowledge, professions, social capital, contingent and cultural factors.

\section{PHYSICIAN-PATIENT RELATIONSHIP: A REVIEW OF THEORETICAL APPROACHES}

\subsection{Health Economics Perspective: An Agency Relationship and Information Assymetry}

From health economic perspective, the physician-patient relation is often perceived as an agency one (Scott, 2000; McGuire and Thomas, 2000; Rexford and Neun 2010: Jones M. A. 2012). The principalagent model stresses the existence of information asymmetry in the interaction between the physician and the patient (Arrow, 1963). In agency relationship, the physician acts like an agent to maximize the patient's utility who is the principal (Arrow, 1963\}. The doctor holds more information about the patient's health status and the available treatments. And the patient has superior knowledge about how these treatments fit with his or her lifestyle and has specific belief about medication and illness (Ong et al., 1995; Stenvenson et al., 2000). The patient communicates theses preferences to the doctor who then act as an agent for the patient. In the perfect agency theory, a specific case of the principal-agent model, the doctor maximizes the patient's utility as it were his own. The model has been extensively used in health economics because of its conceptual simplicity and the lack of agreed alternative. (Stavropoulos, 2012).

\subsubsection{The search of alternative: The Perfect Agent}

In analyzing the agency relationship in healthcare, health economist have tended to ignore the black box of the doctor-patient relationship. Only recently have health economists attempted to re-examine the nature of doctor patient relationship even though asymmetry of information within it is an important source of market failure (Vick, Scott, 1995). Despite the lack of alternative, the principal-agent model prevails but it remains an imperfect agency. A number of economic literatures are working on the concept of perfect agent. What makes a perfect agent in the doctor-patient relationship?

In 1994 Labelle defined the perfect agent as: '...One who makes decision that the patient would have made if the patient possessed the same information and expertise as the agent'. It has been recognized, however that it is impossible to test whether a doctor is a perfect agent using this definition, since the patient will never have the same information and knowledge as a doctor (Ryan and Mooney 1992; Mooney, 1993). Furthermore Evans (1984) suggested that it will be impossible to achieve perfect agency. 'If the agency relationship were complete, the professional would take on entirely the patient's point of view and act if he was the patient. The perfect agent would need a split brain, one half advising the patient solely in the patient's interest, the other half reacting...in a self interested own-welfare maximazing way'.

It is therefore more fruitful to examine the source of imperfect agency and how these can be improved upon. One of these is the extent to which doctors can act in patients' best interests. Central to this is defining what patients' best interests are. It is clear that doctors do, to some extent, have at least part of the patient's utility function in their own utility function (Mooney 1992: Ryan, 1994: Pauly, 1994; Talcott, 1999; Crow et al. 2002). Imperfect agency can arise when the doctor has an incorrect perception of the contents of patient's utility function. There are two aspects to his misperception. The first is that it 
is the patient's welfare or utility that should be maximized rather than some narrow definition of health (Evans, 1984; Mooney and Ryan, 1993). The second way that doctors can misperceive patients' interests is through misperceiving their value about how a given outcome influences their utility (Labelle, 1994).

Both of these sources of imperfect agency can be viewed as traditional sources of information asymmetry in the doctor patient relationship in that patients have more information than the doctor about the contents of their utility function and the value they attach to health and other non-health outcomes (Vick and Scott, !995). Departing from imperfect agency and the perfect agency, how do we consider patient's utility?

\subsubsection{Utility and Utility Anticipation}

Economics uses utility to provide a common measure for the satisfaction derived from the consumption of goods or services. All goods or services provide utility and utility is the sole reason for consumption. From economic perspective, health is considered as a good. It must be understood in term of production process. In contrast with WHO's definition of health as 'a state of physical, mental, and social well being and not merely absence of diseases', Economists captured this insight of people having some say over healthy they are (Rexford and Neun, 2010). Individuals desire healthcare because they enjoy being in good health. Their utility derives from the demand for healthcare. The demand for healthcare are based upon economic literature and works of Grossman (1972), Anderson (1975), Wagstaff (1991), Pohlmeir and Ulrich (1995). While a number of theories focuses on the determinants of health (Murray and Chen, 1993; Evans, 1994). In economy theory utility is usually derived from a good, but Lancaster (1960) argued that the utility derived from the different attributes of goods rather than from the goods themselves.

The utility derived from prevention attribute of goods (e.g vaccination, health education)is called utilityanticipation. It refers to the feeling of well-being which arises from the knowledge that risk of illness and injury are reduced through consumption of prevention goods. It is derived immediately on consumption and continues as a stream of utility over the effective life of the product. (Cohen, 1981). In doctor-patient relationship, the agent may maximize the patient's utility function in the future. The patient's utility function can also be manipulated by the doctors.

\subsubsection{Supplier Induced Demand}

Supplier induced demand results from information asymmetry. Supplier induced demand is qualified as a manipulation of the demand for health care by doctors. A number of studies have examined how doctors influence the demand for health care (Evans, 1974; Richardson, 1981; Hay and Leahy, 1982; Rice, 1984, 1989; Van Doorslaer et al., 1987; Svorny et al., 1987; Rochaix, 1989). The inducement occurs when a physician provides or recommends the provision of medical services that differ from what the patient would choose if or she had available the same information and knowledge as the physician (Rice, 1984). Hay and Leahy (1982) describe suppler-induced demand as: 'services ordered by a physician for a patient that the patient would refuse if he or she had the same medical knowledge and expertise as the physician, but remained the same in all other respects'. Such a definition is very difficult to test for since a patient who is equally as knowledgeable as a doctor is unlikely to exist (Ryan and Mooney 1992).

The agency relationship is based on the assumption of complete information. Yet, information asymmetry is a key element of medical practice that influences their interaction (Arrow, 193). Since the physician is more knowledgeable than the patient, he may have the ability of influencing the demand for health care.

\section{Socio-Anthropological Perspective}

Medical sociologists and anthropologists examine the interaction between doctors and patients in term of power and shared power in treatment decision-making process. 
The doctor-patient relationship is governed by power. As demonstrated the works of Bourdieu $(1977 ; 1996)$, medical power is a social professionalism construction. The physician acquires his power through education, trainings, skills, knowledge and social capital. Medical knowledge whether an art or a science, is appropriated by the doctor as a source of professional power. The physicians' possession and use of medical knowledge constitute their scientific authority; physicians' power derives from their ability to create objectives, representations, of the patient's health or illness (Weiss, 1997). Medicalization is also source of medical power. The notion of medicalization has been applied by Foucault in analysis between state and its population, between power and individual subject. Medicalization describe a process where more and more aspects of human existence, human behavior and human body are reframed as medical issues and where the professional power of medicine expands over wider sphere of life (Foucault, 1975; 1986; 1994; 2000). Medicalization induces bio-power. The concept of bio-power seems unavoidable in studies of health and illness, not only in the most obvious forms of institutional power or authoritative power as demonstrated in healthcare institution, but also but the configuration of power in specific social setting in more subtle form of self discipline as pointed out Foucault. His study of power is not formed as attack on the exercise of power by specific institutions, groups, elites, but rather a study of the techniques or the forms of power as enacted in relations between individual agents and incorporated in each individual (Helle and Vibeke, 2004).

In this context, Friedson's work $(1961,1970,1983,1986)$ demonstrated that medical profession had extended its monopoly over health and illness both through subordination of exclusion of other health work occupations such as nursing and through control of the process of diagnosis treatment and hospitalization. Medical dominance was achieved through occupational closure and control of the division of labor (Freidson, 1970, 1986). Occupational closure refers to a medical monopoly of the profession.

The physician-patient relationship needs to be redefined to allow both the physician and patient to take an active role in treatment decision. Medical sociologists and anthropologists have conceptualized the physician-patient relationship in variety ways (Parson, 1952; Ezekiel and Linda, 1992).

\subsection{The Parsonsian Model}

Parson's (1952) conceptualization of doctors and patients was primarily focused on professional role. In functionalism the patient role was largely to be obedient and responsive, in ways that the doctor required and controlled. As a functionalist theorist, Parsons viewed illness as a form of dysfunctional deviance that required reintegration with the social organism (Hughes 1994). In this context, the role of the physician was to reintegrate the patient with the social system.

Inter-actionist sociologists and ethno-methodologists, on the other hand have emphasized negotiation and conflict, they have played an important part in creating the active patient, the subject rather than the object of the study. In their research, patients are individuals who care about their social world. Their motivations and their actions are complex and it is the role of interpretive sociology to lease out, construct and sustain the personal identity of each individual actor (Linda, 1994).

\subsection{The Four Models}

Ezekiel and Linda's work (1992) described four models of physician-patient relationship: the paternalistic model, the informative model, the interpretive model and the deliberative model. In these models our focus are on physician's responsibility and the patient's autonomy.

\subsubsection{The Paternalistic Model}

In medical perspective, bio-power is explained in term of paternalism. In the interaction between physicians and patient, the physician acts as parent. The information is one way. The physician is the 
sender and the patient is the receiver. The patient is considered as a child. A number of sociological and anthropological literatures inform on the paternalistic culture which find its foundation on the historical and philosophical background of Hippocratic medicine (Dunn, 1994; Olafson, 1994; Howard, 1987; Stumpf and Fieser, 2003). In this traditional approach, little attention has been paid to the patient's autonomy. Patient plays a passive role (Coulter, 2002). In this model, the physician acts as the patient guardian, articulating, implementing what is best for the patient. In this context, the physician's responsibility is to place the patient's above other interests. One of the best examples of paternalism is the appropriation of medical record by the physician. In the last decade the model has been subject to many criticisms. Anthropologists and sociologists still view paternalistic physician as a Victorian patriarch (Arras, 1998; Gillon, 1994). As an analogy, informative, interpretive and deliberative sociologists consider the patient as an object rather than a subject.

\subsubsection{The Informative Model}

The information model is sometimes called; the scientific, engineering or consumer model (Ezekiel et al. 1992) and also called informed decision making model (Stavropoulou, 2012). In this model the objective of the physician-patient interaction is for the physician to provide the patient with all relevant information, for the patient to select the medical interventions he or she wants, and for the physician to execute the selected interventions. A patient must be fully informed about and understand the potential benefits and risks of their choice of treatment.

The informative model assumes a fairly clear distinction between facts and values. The patient's values are well defined and known. What the patient lacks is a fact. It is the physician's responsibility to provide all available facts, and the patients then determine what treatments are to be given. There is no role for physician's values, the physician's understand of the patient's values, or his or her judgment of the worth of the patient's values. In the informative model, the physician is a surveyor or technical expertise providing the patient with the means exercise control. As a technical expert, the physician has important obligations to provide truthful information, to maintain competence in his area of expertise, and to consult others when their knowledge or skills are lacking. The conception of patient autonomy is patient control over medical decision-making (Ezekiel et al., 1992). The informative model is close to the doctrine of informed patient contained in the statutes of many countries (Pence 1995; William et al. 2008; Charles 1997, 1999).

\subsubsection{The Interpretive Model}

As demonstrated in his work, the interpretive model in the doctor-patient relationship aims at elucidating the patient's values and what he or she actually want and to help the patient select the available medical interventions that realize these values. Like the informative physician, the interpretative physician provides the patient with information on the nature of the condition and risks and benefit of possible interventions. In the interpretative model, the physician is considered as a counselor analogue to cabinet minister's advisory role to head of state, supplying relevant information, helping to elucidate values and suggesting what medical interventions realize these values. Thus the physician's obligations are those enumerated in the informative model but also require engaging the patient in joint process of understanding. According ly, the concept of patient autonomy is self-understanding; the patient comes to know more clearly who he or she is and how the various medical options bear on his or her identity (Ezekiel et al. 1992).

\subsubsection{The Deliberative Model}

The deliberative model in physician-patient relationship aims to help the patient determine and choose the best health-related values that can be realized in the clinical situation. To this end, the physician must delineate information on the patient's clinical situation and then help elucidate the types of values 
embodied in the available option. In the deliberative model, the physician act as a teacher or friend engaging the patient in dialogue on what course of action would be the best (Ezekiel et al. 1992; Charles C. et al. 1997). The conception of patient autonomy is moral self development (Ezekiel et al. 1992)..

\section{Findings: Comparing of the Models}

The physician- patient relation interaction models are especially based upon the physician's behavior and the patient's autonomy (Table 1)

Table 1. Physician-Patient Relationship Models

\begin{tabular}{|l|l|l|}
\hline Models & Physician's Behavior & $\begin{array}{l}\text { Conception of Patient } \\
\text { Autonomy }\end{array}$ \\
\hline Parsonsian & Parent & Child \\
\hline Hippocratic & Parent & Child \\
\hline Informative & Surveyor -Technical Expectise & Self-Control \\
\hline Interpretative & Counselor & Self-Understanding \\
\hline Deliberative & Teacher - Friend & Self Development \\
\hline
\end{tabular}

Source: Adapted From Ezekiel (1992)

The five models are not exhaustive. A number of other models have examined the physician-patient interaction: Marxist and Feminist Approaches (Doyal and Gough, 1991); the Instrumental Model in which the moral interest of the patient is not taken into account (Jones, 1981; Brant, 1978). A number of other socio-anthropological literatures have discussed the physician-patient interaction: the medical monopoly aspect of medicine (Freidson, 1970): the social production of health and illness (Doyal, 1979): the inter-actionist (Blumer, 1969) and the social action theory (Donovan, 1986).

\section{Physician-Patient Relationship and Health Regulation Implications}

Departing from economic model, health regulators look at the regulation of supply and demand side in the physician-patient interaction. As demonstrated the works of health economics theorists, information asymmetry, agency relationship, supplier-induced demand and patient's maximization utility are key issues in the physician-patient interaction. These key issues need to be addressed by many health systems and health regulators.

In the agency relationship, the physician acts on behalf of the patient to restore his or her good health or to maximize his or her utility. In this process, the physician may go beyond this motive. The research in health economics shows the physician's behavior can be influenced by many other factors: altruism, selfinterests behavior, such as income, reputation and purchasing power (Stavrapoulou, 2012). From this point, health regulators should act on the supply side of health care service to reduce the information asymmetry and the demand inducement. The information asymmetry can de reduced through empowerment and education of the patient. Unnecessary treatment and prescription can be avoided by the use of medical guidelines and references. One of the best examples of supply side regulation is the introduction of General Practitioners as 'Gate Keeper' in the National Health System, (UK). A number of studies have described method supply side regulation: cost containment, Diagnosis Related Groups (DRGs) among others: medical records and budget (Donaldson, and Magnussen. 1991).

On the other hand, health consumers are increasingly well educated and empowered on health. A number of disciplines such as health communication, health education, healthcare marketing, and health promotion have contributed to the growth of consumerism and demand for health. On the demand side, many countries have restricted access to healthcare through introduction of hospitalization fees, cost sharing and health insurance. 


\section{Discussion}

From the review of the health economics and socio-anthropological perspectives, asymmetry information is persisting as well as demand inducement. Medical sociologists argued that power is rooted in the physician- patient-relationship. Medical sociology theorists argued that the medical profession had extended its monopoly over health and illness both through subordination or exclusion of other health workers occupations such as nursing and through control of process diagnosis, treatment and hospitalization (Jones, 1994). In consensus theory medical knowledge about illness was seen as paramount; people took their symptoms to be diagnosed and doctors claimed neutral and objective status for their theories and classifications of diseases. Illness was actually negotiated through lay culture (Jones, 1994). Field of power in medical field has been constructed by many governments with his bureaucratic institutions supported by medical bodies (Samuelsen, 2004). A number of literatures have especially supported the construction of medical power in developing world (Samuelsen and Vikebe, 2004; Meinert, 2004).

Marxists and inter-actionist theorists have also discussed the physician patient interaction.

Marxist theorists have criticized all the models. Marxists look at the physician-patient interaction in term of social class. Marxists claim that, although capitalism and professionalized medicine have improved the standard of living of living, there are still glaring global and social inequality in health work -a social class gradients- and there is still evidence of class conflict in health work (Jones, 1994). Doyal (1979) has argued that the way health and illness are defined, as well as the material reality of disease and health will vary according to the social and economic environment in which they occur. A number of health systems both in advanced industrialized countries and less industrialized countries, have put in place health legislations to reduce social inequality in health. For example The National Health System in UK and the Social Security in France are tools for reduction of inequality in health. Among others, the introduction of Medicare and Medicaid as social institutions to assist the elderly and poor in the USA..

\section{Conclusion}

In conclusion, we have used the health economics and socio-anthropological models to examine the physician-patient interaction. The first approach is based on agency relationship in which the physician acts on behalf of the patient. In this approach, the interaction is dominated by the information asymmetry between the two actors. The socio- anthropological examines the physician-patient relationship in term power. The autonomy of the patient remains one of the challenges in the physician-patient relationship. Other perspectives: such as psychology and medical law have also explored the physician-patient interaction.

\section{References}

Anderson R. M. (1975). Introduction in Anderson R. M., Kravits J., AndersonO. W. (eds), Health Services, Boston, Ballinger Publishing Company, pp. 3-8.

Arras D., Steinbock B. (1998). Ethical Issues in Modern Medicine, (5 ${ }^{\text {th }}$ Ed.), Mountain View, Calif.: Mayfield.

Arrow K. (1963). Uncertainty and the welfare economics of medical care, American Economic Review. 53 (5) 941-73.

Blumer H. (1969). Symbolic Interactionism; Perspective and Method. New Jersey, Prentice Hall.

Bourdieu P. (1977). Outline of a Theory of Practice. Cambridge University Press. Cambridge. 
Bourdieu P. (1996). Understanding, Theory, Culture and Society, vol. 2, pp. 17-37.

Brandt A. M. 91978). Racism and research: the case of the Tuskegee Syphilis Study. Hasting Cent Rep, 21-29.

Calcott P. (1999). Demand inducement as cheap talk. Health Economics, 8 (8), pp. 721-733.

Charles C., Gafni A., Whelan T. (1997). Share decision -making in the medical encounter: What does it mean? (or it takes at least two to tango), Social Science and Medicine, 44. 681-92.

Charles C., Gafni A., Whelan T. (1999). Decision-making in the physician-patient accounter: revisiting the shared treatment decision-making model. Social Science and Medicine, 49. 651-61.

Cohen R. D. (1981). Health education and the economic theory of demand. Discussion Paper No. 08/81, Health Economic research Unit. University of Aberdeen.

Coulter A. (2002). The Autonomous Patients: Ending Paternalism in Medical Care, London, UK, Stationery Office (for the Nuffield Trust).

Crow R., Gage S., Hampson S., Storey S., Thomas H. (2002). The measurement of satisfaction with healthcare implications for practice from a systematic review of the literature. Health Technology Assessment 6(32), 1-244.

Donaldson C., Magnussen J. 1991). DRGs: the road for hospital efficiency? Heath Economics Research Unit Discussion Paper 09/91. University of Aberdeen.

Donovan J. (1986). We Don't Buy Sickness, it Just Comes. Aldershot, Gower.

Doyal L., Gough I. (1991). Towards a Theory of Human Needs. London. MacMillan

Doyal L., Pennell J. (1979). The Political Economy of Health. London, Pluto Press.

Dunn, H. P. (1994). Ethics for doctors, nurses, and patients, Staten Island, NY, USA: Alba House.

Evans R. G. (1974). Supplier-induced demand. Some empirical evidence and implications in M. Perlman (ed). The Economic of Health and Medical Care, North Holland, Amsterdam.

Evans, R.G. (1994). Introduction in Evans R.G., Barer M. L., Marmor T. R. (eds). We are some people Healthy and Others not? Berlin Walter Cruyter.

Ezekiel J. E., Linda L. E. (1992). Four models of the physician-patient relationship, The Journal of the American Medical Association. April22, v267 n6 p222 (6).

Foucault M. (1975). The Birth and the Clinic, Vintage Books, New York.

Foucault M. (1986). The Archeology of knowledge, Tavistock, London

Foucault M. (1994). The Order of Things: An Archeology of the Human Sciences, Vintage Books, New York.

Foucault M. (2000). Essential Works of Foucault 1954-1984. Power, vol. 3, Penguin Books, London.

Friedson E. (1961). Patents' View of Medical Practice. New York, Sage. 
Friedson E. (1970). Profession of Medicine: A Study of in the Sociology of Applied Knowledge. New York, Dood Mead.

Friedson E. (1983). The theory of professions - state of the art, in Dingwall R.and Lewis P. (eds) The Sociology of Professions. London, MacMillan.

Friedson E. (1986). Professional Powers. The Institutionalization of formal Knowledge. London, University of Chicago.

Gillon R., Lloyd, A. (1994). Principles of health Care Ethics: Criticism and defence of the canonical medical ethics principles of autonomy, beneficence, non-maleficence and justice. Baltimore: John Wiley and Sons.

Grossman M. (1972). The demand for health: a theoretical and empirical investigation. National Bureau of Economic Research Occasional Paper No. 119, New York: National Bureau of Economic Research.

Hay J., Leahy M. J. (1982). Physician-induced demand: an empirical analysis of the consumer information gap. Journal of Health Economics 1: 231-244.

Helle S., Vibeke S. (2004). The relevance of Foucault and Bourdieu for medical anthropology: Exploring new sites. Anthropology and Medicine, vol. 11, no. 1, pp. 3-10.

Hughes J. (1994). The Doctor-Patient Relationship in Hughes J. Organization and Information at the bedSide. PhD Dissertation, UMI.

Jones J., L. (1994). The Social Context of Heath and Health Work. Macmillan. London.

Jones J. H. (1981). Bad Blood. Free Press. New York.

Jones M. A. (2012). The Elgar Companion to health economics. Edward Elgar Publishing. Cheltenham. UK.

Kaba R., Soriakumaran P. (2007). The evolution of the doctor-patient relationship. International Journal of Surgery, 5(1), 57-65.

Labelle R., Stoddart G., Rice T. (1994). A re-examination of the meaning and importance of supplier induced demand. Journal of Health Economics. 13:347-368.

Lancaster K. (1960). A new approach to economic theory. Journal of Political Economy, April, 1960.

Linda J. J. (1994). The Socia Context of Health and Health Work, MacMillan Press Ltd, Houndmills, Basingstoke, Hampshire and London.

McGuire A., Costa-Font(2012). The LSE companion to health policy. Edwrd Elgar. Cheltenham. UK.

McGuire, Thomas G. (2000) Physician Agency in Anthony J., Culyer and and Joseph P. Newhouse (eds). Handbook of Health Economics, Amsterdam Elsevier Science, pp. 461-536.

Meinert I. (2004). Resources for health in Uganda. Bourdieu's concepts of capital and habitus, Anthropology and Medicine, Vol. 11, No. 1, pp. 11-26.

Mooney G. (1992). What do we want from our healthcare services? What can we expect from our physician? Policy Commentary C92-1, Center for Health Economics and Policy Analysis, McMaster University. 
Mooney G., Ryan M. (1993). Agency in health care. Getting beyond first principles. Journal of Health Economics. 12(3) pp. 125-135.

Murray C. J. L. and Chen, L. C. (1993)In search of a contemporary theory for understanding mortality change, Social Science and Medicine, 36(2), 143-55.

Olafson A. (1994)., F. Principles and persons. An Ethical interpretation of Existentialism, The Johns Hopkins Press Ltd: London.

Ong, L. M., J. C. de Haes, A. M.Hoos, F. B.(1995). Doctor-patient communication: a review of the literature. Social Science and Medicine 40(7) 903-18.

Parson T. (1952). Illness, Therapy and the Modern Urban Family, Journal of Social Issues, 8, pp. 31-44.

Pauly M. V. (1994). Editorial: a re-examination of the meaning and importance of supplier induced demand. Journal of Health Economics, 13: 369-372.

Pence G. (1995). Classic Cases in Medical Ethics. (2 ${ }^{\text {nd }}$ Ed.), New York MacGraw Hill.

Pohlmeir, W. and Ulrich V. (1995). An econometric model of the two-part decision-making in the demand for health care, Journal of Human Resources, 30(2), 339-61.

Rexford E. S., Neun P. S. (2010). Health Economics. Theories, Insights and Industry Studies. South Western. CENGAGE Learning Australia. United States.

Rice 1T., Labelle R. J. (1989). Do physicians induce demand for medical services? Journal of Health Economics. 14: 587-600.

Rice T. (1984) Physician initiated demand for health services. Journal of Health Economics. 14: 584625.

Richardson J. (1981). The inducement hypothesis: that doctors generate demand for their own services. In J. van der Gaag and M. Perlman (ed). Health, economics and health economics. North Holland, Amsterdam

Rochaix L. (1989). Information asymmetry and search in the market for physicians' services. Journal of Health Economics. 8: 53-84.

Ryan M. (1994). Agency in health care: lessons for economists from sociologists. American Journal of Economics and Sociology, 53: 207-218.

Ryan M., Mooney G. (1992). Supplier induced demand: where are and where should we go? Discussion Paper 05/92. Health Economic Research Unit. University of Aberdeen.

Samuelsen H. (2004). Therapeutics itineraries: the medical field in rural Burkina Faso. Anthropology and Medicine, Vol. 11, No. 1, pp. 27-41.

Samuelsen H., Vibeke S. (2004). The relevant of Foucault and Bourdieu for medical anthropology: Exploring new sites. Anthropology and Medicine, Vol. 11, No. 1, pp. 3-10

Scot, Anthony (2000). Economic of general practice in Anthony J., Culyer and and Joseph P. Newhouse (eds). Handbook of Health Economics, Amsterdam Elsevier Science, pp. 175-200. 
Stavropoulou C. (2012). The doctor-patient relationship: a review of theory and policy implications in McGuire A., Costa-Font(eds). The LSE companion to health policy. Edwrd Elgar. Cheltenham. UK, pp. 314-326.

Stevenson F. A, Barry C. A, Britten N, Barber N, Bradley C. P. (2000). Doctor-patient communication about drugs: the evidence for shared decision making. Social Science and Medicine 50(6) 829-40.

Stumpf E., Fieser J. (2003). Socrates to Sartre and beyond: A History of Philosophy, $7^{\text {th }}$ ed. New York: McGraw Hill.

Svorny S. S. (1987). Physician Licensure: A new Approach to Examine the Role of Professional Interests. Economic Inquiry. pp. 497-509.

Van Doorslaer E., Geurts J. (1987). Supplier-induced demand for physiotherapy in the Netherlands. Social Science and Medicine. 24: 919-925.

Vick S., Scott A. (1995). What makes a perfect agent? A pilot study of patients preferences in the doctorpatient relationship. Discussion Paper 05/95. Health Economic Research Unit. University of Aberdeen.

Wagstaff A., Paci P., van Doorslaer (1991). On the measurement of inequalities in health, Social Science and Medicine, 33(5), 545-57.

Weiss M. (1997). For doctors eyes only: medical records in two Israeli hospitals. Culture, Medicine and Psychiatry. 21: (3) 283-302.

William S., Torrens P. (2008). Introduction to health services. ( $7^{\text {th }}$ Ed.), Clifton Park, NY, Delmar Cengage Learning.

Wrede S., Benoit c., Bourgeault I, van Teijlingen, Sandall J., Devries R. (2006). De-centered comparative research context sensitive analysis of maternal health care. Social Science and Medicine, 6(3), 286-297. 